\title{
Evaluation of the antioxidant activity of some types of red and white wines
}

\author{
Ana LEAHU*, Sonia AMARIEI, Cristina DAMIAN, Mircea OROIAN and Sorina ROPCIUC \\ Stefan cel Mare University of Suceava, Romania, Faculty of Food Engineering, 13th University Street, Suceava, \\ Romania
}

\begin{abstract}
Samples of commercially available Romanian wines were analyzed in order to determine total phenols content and the antioxidant activity. The content of total phenolics in the extracts was determined according to the Folin-Ciocalteu method and calculated as gallic acid equivalents (mg GAE/100g). Antiradical activities of the extracts were evaluated by a micro assay using 1, 1ф-diphenyl-2-picrylhydrazyl spectrophotometric method. Wine characteristics measurements were examined by multivariate data analysis, using principal component analysis (PCA). Total polyphenol content was correlated to the antioxidant activity of the studied wine samples. The values of the inhibition power of free radical, PI\%, are ranging between 1.68 for white wine and 0.95 for red wine ("Bull blood" bottled by Tohani winery, Prahova, Romania).
\end{abstract}

Keywords: wines, free radical scavenging activities, antioxidant activity; health promotion; phenolic.

\section{Introduction}

Polyphenols are classified as antioxidants whose main action is to prevent the formation of free radicals, fighting skin aging. Can be discovered in some fruits and vegetables and are in the form of anthocyanins (in red fruits), flavonoids (in citrus fruits), quercetin (in tea leaves, chocolate, onions, seaweed and apple).

Natural polyphenol can range from simple molecules (phenolic acids, henylpropanoids, flavonoids) to highly polymerized compounds (lignins, melanins, tannins), with flavonoids representing the most common and widely distributed subgroup [1].

Grapes and wine phenolic compounds can be divided into non-flavonoid compounds and flavonoid compounds. Studies regarding the phenolic compounds of wine and grapes represent an important focus, because of their health benefits. Use of small quantities of wine and after middle ages, it is beneficial in certain diseases such as: heart disease, diabetes, duodenal ulcer and some infections. Recent research shows that wine phenolic compounds can induce blood vessels to relax, allowing better circulation of blood, thereby protecting against the development of coronary heart disease.

A study conducted by M.S. Fernández-Pachón et al., 2004 showed that the antioxidant activity of red wines is higher than that of white or sherry wines with every method under study (oxygen radical absorbance capacity (ORAC), 2,2-azinobis(3-ethylbenzothiazoline)-6 sulfonic acid (ABTS) and 1,1-diphenyl-2-picrylhydrazyl (DPPH). High correlation coefficients were found between the total polyphenolic index (TPI) and antioxidant activity measured by ABTS, DPPH and ORAC methods when the whole set of samples is considered [2]. Antioxidant capacity is influenced by solvent extraction, storage temperature $[3,4,5]$.

It should be noted, however, that the phenolic compounds from the grape in addition to their antioxidant activity, contribute to the color of the wine, are involved in many oxidation reactions and play an important role in the maturation of wines $[6$, 7]. 
After analyzing the polyphenolic contents of twenty-three samples of red wine selected from different grape varieties grown in Sicily and evaluating the correlation between antioxidant capacity and total polyphenolic contents, it resulted that wines such as Merlot 2003 or CabernetSauvignon 2003 have high concentrations of catechine and higher antioxidant capacity values; on the contrary, others types like Souvignon 2003 or Souvignon-Merlot 2002, have lower values of catechin and consequently of antioxidant capacity [8].

There is a very good connection between the antioxidant activity, determined by using the DPPH method, and the content in total polyphenolic compounds $\left(r^{2}=0.92\right)$ in the analysis of the 43 red wines from Arlanza region (Spain) [9].

The wines obtained by conventional maceration/ fermentation (PO) present the highest color intensity and polyphenolic content [10].

The purpose of this study was to evaluate the correlation between antioxidant capacity and total polyphenolic contents, in different red and white wines.

\section{Experimental}

\subsection{Wine samples.}

Three red wines and three white wines produced from different grape varieties grown in Romania were used in the study (Table 1). Wines cover viticulture areas of Romania, they are available in the Romanian market. All samples were and analyzed shortly after opening.

\subsection{Chemicals}

2,2-diphenyl-1-picrylhydrazil radical (DPPH) and Folin-Ciocalteu's reagent used for experiments were purchased from Sigma - Aldrich. The methanolic solutions of DPPH $(5 \mathrm{mg} / \mathrm{mL})$ and of freshly prepared Folin Ciocalteu reagent $(1: 10$, v/v, with water) were prepared. All other reagents used were of analytical grade purity. Deionizer water was used. Absorption determination for total polyphenols content was made using UV-VIS spectrophotometer.
Table 1. Wine samples

\begin{tabular}{|c|l|l|}
\hline Sample & Sample type/bottling year & Winery \\
\hline S1 & $\begin{array}{l}\text { Crăiţa Transilvaniei/red } \\
\text { wine/2011 }\end{array}$ & $\begin{array}{l}\text { Dealurile } \\
\text { Transilvaniei }\end{array}$ \\
\hline S2 & $\begin{array}{l}\text { Merlot\&Cabernet } \\
\text { Saugvinon/ red wine/2011 }\end{array}$ & $\begin{array}{l}\text { S.C. Vincon } \\
\text { Vrancea S.A. }\end{array}$ \\
\hline S3 & Bull blood/ red wine/2012 & Tohani \\
\hline S4 & Feteasca/white wine/2011 & Jidvei \\
\hline S5 & $\begin{array}{l}\text { Saugvinon Blanc/ white } \\
\text { wine/2011 }\end{array}$ & $\begin{array}{l}\text { Sarica } \\
\text { Niculiţel }\end{array}$ \\
\hline S6 & $\begin{array}{l}\text { Chardonay/white } \\
\text { wine/2011 }\end{array}$ & Recaş \\
\hline
\end{tabular}

\subsection{General chemical analyses}

Alcohol content, total extract and titratable acidity were determined using the methods from OIV (2006), [11]. All analytical determinations were performed at least in triplicate. Values of different parameters were expressed as the mean of all measurements.

2.4. Total polyphenol content [12] was determined using the Folin Ciocalteu method. Samples of wine were extracted with $80 \%$ ethanol $(0.1 \mathrm{ml}$ sample $/ 10 \mathrm{~mL}$ of $80 \%$ ethanol), and total phenol contents (TPC) of the extracts were determined. The wine samples aliquot $(0.2 \mathrm{~mL})$ was added to $1.5 \mathrm{~mL}$ of freshly prepared Folin Ciocalteu reagent $(1: 10$, $\mathrm{v} / \mathrm{v}$, with water). The mixture was allowed to equilibrate for $5 \mathrm{~min}$ and then mixed with $1.5 \mathrm{~mL}$ of $60 \mathrm{~g} / \mathrm{L}$ sodium carbonate solution. After incubation at room temperature for $120 \mathrm{~min}$, the absorbance of the mixture was read at $760 \mathrm{~nm}$ using the respective solvent as blank. The results were expressed as $\mathrm{mg}$ of gallic acid equivalents (mg GAE). The correlation coefficient for the calibration curve was 0.9954 . Results were expressed as gallic acid equivalents per liter wine.

\subsection{2,2-Di (4-tert-octylphenyl)-1-pycrilhydrazyl (DPPH) scavenging capacity assay}

The method used for determining the antioxidant activity of wine is based on scavenging 2,2-Di (4-tert-octylphenyl)-1-picrylhydrazyl (DPPH) radicals $[5,13,14]$. The fruit samples aliquot $(0.5$ $\mathrm{mL}$ ) was added to freshly prepared DPPH reagent. After incubating for $5 \mathrm{~min}$, the absorbance of the 
resulting solutions was measured at $517 \mathrm{~nm}$ using a spectrophotometer. The control was conducted in the same manner, except that distilled water was used instead of sample.

Using a calibration curve with different amounts of $\mathrm{DPPH}$, the $\mathrm{IC}_{50}$ was calculated. The $\mathrm{IC}_{50}$ is the concentration of an antioxidant that is required to quench $50 \%$ of the initial DPPH radicals under the experimental conditions given.

\subsection{Statistical analysis.}

Pearson correlation coefficient between total phenolic and scavenging activity was made using Microsoft Excel 2007 software. The PCA was performed using Unscrambler X 10.1 (CAMO Process AS, Oslo, Norway), all the physicochemical parameters were weighted and normalized for performing the PCA. The PCA was applied to describe the relationship among the antioxidant capacity and total polyphenolic contents.

\section{Results and Discussions}

\subsection{General chemical analysis}

The characteristics of samples, obtained by chemical analysis, are presented in Table 2 . Considering the analyzed samples, the alcoholic concentration did not have significant variations between $11.15 \%$ v/v (sample Craita Transilvaniei) and $12.52 \% \mathrm{v} / \mathrm{v}$ (sample Feteasca White). The values of the Alcohol content $(>10.5 \%$ volume) show that the six wines can be placed in the category of superior wines.

Total acidity, provides physico-chemical stability to wine and gives its bright colour and fresh taste. Total acidity and volatile acidity are directly connected to its sensorial assessment [15].

3.2. Polyphenol content and free radical scavenging capacity were studied in conventional red and white wines.

The six samples wines present different amounts of TP, the highest amount being registered in red wine Merlot\&Cabernet 2011 vintage (1084.4 mgGAE/L). Romanian variety Bull blood is also a wine with high content of total phenolics (597.2 mgGAE/L). Saugvinon Blanc wine presents the lowest amount of total phenolics (125 mgGAE/l 2011 vintage). Similar results were obtained by different authors [16, 17]. Total polyphenol content of wines from Spanish and Croatian regions are between 851 and $3264 \mathrm{mg} / \mathrm{L}$ [17].

There is a low linear correlation between the phenolic components and the antioxidant activity of Sicilian red wine [8]. It can be seen that Romanian wines, on the content of polyphenols, within the limits of the other wines reds studied, except that the latest have the upper more than Romanian wines. This may be explained by the climatic conditions, soil type, vine cultivation practices and different grape varieties, methods of processing and ageing.

Table 2. Total polyphenols and \% inhibition in the analyzed wines

\begin{tabular}{|l|l|l|l|c|c|c|c|}
\hline & Sample type & $\begin{array}{l}\text { Total acidity } \\
\text { tartaric } \\
\text { acid) }(\mathrm{g} / \mathrm{l})\end{array}$ & $\begin{array}{l}\text { Volatile acidity } \\
\text { (acetic acid) } \\
(\mathrm{g} / \mathrm{l})\end{array}$ & $\begin{array}{l}\text { Alcohol } \\
\text { content } \\
(\mathrm{vol} /)\end{array}$ & $\begin{array}{l}\text { Total } \\
\text { extract } \\
(\mathrm{g} / \mathrm{l})\end{array}$ & $\begin{array}{l}\text { TP } \\
(\mathrm{mg} \text { GAE } / \mathrm{L})\end{array}$ & $\mathrm{IC}_{50}$ \\
\hline P1 & $\begin{array}{l}\text { Crăiţa } \\
\text { Transilvaniei }\end{array}$ & 5.09 & 0.57 & 11.15 & 21.4 & $921.6 \pm 1.25$ & 1.04 \\
\hline P2 & Merlot\&Cabernet & 6.13 & 0.61 & 12.10 & 25.12 & $1084.4 \pm 4.58$ & 1.28 \\
\hline P3 & Bull blood & 7.84 & 1.68 & 12.31 & 28.65 & $597.2 \pm 3.12$ & 0.95 \\
\hline P4 & Feteasca & 6.1 & 0.55 & 12.52 & 20.5 & $235 \pm 1.49$ & 6.25 \\
\hline P5 & Saugvinon Blanc & 6.2 & 0.56 & 11.80 & 19.52 & $225 \pm 1.64$ & 7.35 \\
\hline P6 & Chardonay & 5.8 & 0.44 & 12.14 & 19.12 & $294 \pm 2.64$ & 7.85 \\
\hline
\end{tabular}

$\mathrm{TP}$ - total polyphenols expressed as gallic acid equivalents

$\mathrm{IC}_{50}=$ Free Radical Scavenging Activities, for the antiradical activity measurements, samples were diluted 1:10. 
Table 3 Correlation matrix for the variables measured in red wines samples

\begin{tabular}{|l|c|c|c|c|c|c|}
\hline \multicolumn{1}{|c|}{ Variables } & Total acidity & Volatile acidity & Alcohol content & Total extract & TP $\mathrm{mg}$ & $\mathrm{IC}_{50}$ \\
\hline Total acidity & $\mathbf{1}$ & & & & & \\
\hline Volatile acidity & $\mathbf{0 . 9 8 6}$ & $\mathbf{1}$ & & & & \\
\hline Alcohol content & -0.113 & 0.054 & $\mathbf{1}$ & & & \\
\hline Total extract & 0.537 & 0.670 & $\mathbf{0 . 7 7 8}$ & $\mathbf{1}$ & & \\
\hline TP mg & -0.994 & $\mathbf{- 0 . 9 9 8}$ & 0.005 & -0.625 & $\mathbf{1}$ & \\
\hline IC $_{50}$ & -0.558 & -0.688 & -0.762 & $\mathbf{- 1 . 0 0 0}$ & 0.644 & $\mathbf{1}$ \\
\hline
\end{tabular}

Table 4 Correlation matrix for the variables measured in white wines samples

\begin{tabular}{|c|c|c|c|c|c|c|}
\hline Variables & $\begin{array}{c}\text { Total } \\
\text { acidity }\end{array}$ & $\begin{array}{c}\text { Volatile } \\
\text { acidity }\end{array}$ & $\begin{array}{l}\text { Alcohol } \\
\text { content }\end{array}$ & $\begin{array}{l}\text { Total } \\
\text { extract }\end{array}$ & TP mg & $\mathrm{IC}_{50}$ \\
\hline Total acidity & 1 & & & & & \\
\hline Volatile acidity & 0.939 & 1 & & & & \\
\hline Alcohol content & 0.569 & 0.250 & 1 & & & \\
\hline Total extract & 0.988 & 0.874 & 0.689 & 1 & & \\
\hline TP mg & -0.753 & -0.934 & 0.113 & -0.642 & 1 & \\
\hline $\mathrm{IC}_{50}$ & -0.396 & -0.688 & 0.530 & -0.249 & 0.902 & 1 \\
\hline
\end{tabular}

Links correlative matrix determined by Pearson red wines analyzed, shows the highest significant negatively correlation $(r=-1.000)$ between the total extract and antioxidant activity (Table 3 ). This correlation characterized only varieties of red wine. The correlation value for the parameters total extract and total acidity measured in the selected white wines is 0.988 , showing that there is strong correlation between these two parameters (Table 4). The highest negatively correlation have been observed in the case of total poliphenols with volatile acidity $(r=-0.934)$, (Table 4).

\subsection{Antioxidant activity}

The lowest $\mathrm{IC}_{50}$ value indicates the highest antioxidant activity of the complex against the effects of free radicals. The free radicals are involved in the process of lipid per oxidation and have a decisive role in the development of numerous chronic diseases, such as cancer and cardiovascular diseases.

As reported in Table 2, in 2012 it is the Bull blood $(0.95 \%)$, the variety showing the highest antioxidant power; according table 2 the reported antioxidant capacity values ranged from 0.95 to 7.85 $\%$.

Based on the DPPH method, antioxidant capacity, was in order: Bull blood > Crăiţa Transilvaniei > Merlot\&Cabernet $>$ Feteasca > Saugvinon Blanc $>$ Chardonay.

Red wines in general display great variations in antioxidant capacity when evaluated as fresh samples by the DPPH method. However, compared to findings published elsewhere $[2,8,17,18]$, the wines samples included in our study ranked relatively high. Romanian variety Royal Maiden presents the highest radical scavenging activity [19].

A major correlation exists between antioxidant activity and content of polyphenols $(r=0.902)$ for 
white wines samples analyzed. High correlation coefficients were found between the total polyphenolic index (TPI) and antioxidant activity measured by ABTS, DPPH and ORAC methods of different types of wines (red wine, white wine and sherry wine) [2].

According this research, if protection from oxidation of proteins is assessed, (ORAC assay) red wines are five-fold more active than white wines [2].

The significant correlation found between antioxidant activity and the total polyphenol index (TPI) in all red wines made from two Vitis vinifera grape varieties grown in NW Spain (viz. Mencía and Brancellao) during bottled storage in the dark for 12 months $(r>0.88)$ [20].

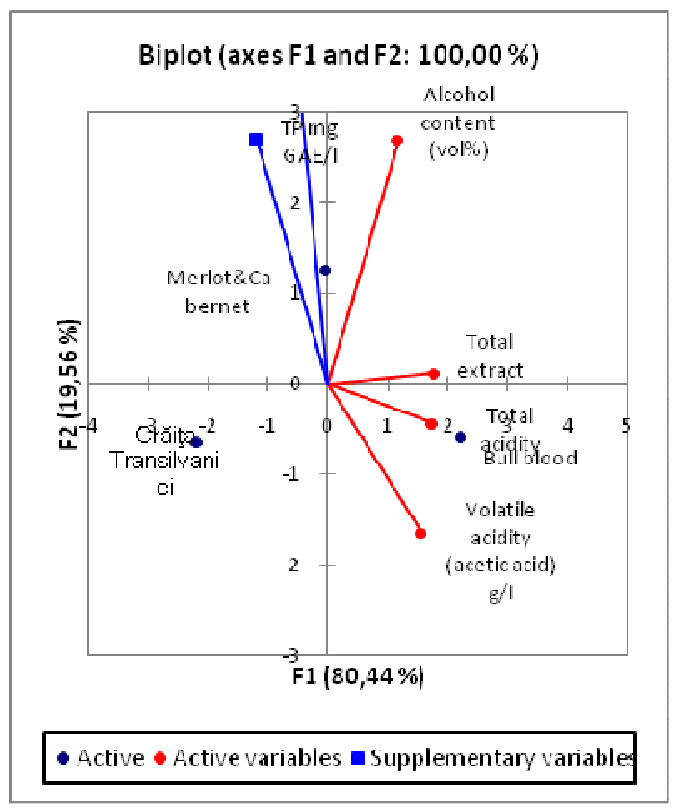

Fig. 1. The relation between the content of total phenols and antioxidant activity in the analyzed red wines samples

Analysis of differentiated varieties of red wine and white wine with qualitative variables and total polyphenol antioxidant activity (Fig. 1 and Fig. 2) shows that the range of red wine Merlot \& Cabernet presents the best and most antioxidant activity, high content in polyphenols, with the correlation ratio of $80.44 \%$.
On the white wine varieties, the highest polyphenol content has Chardonnay, with the correlation ratio of $64.36 \%$.

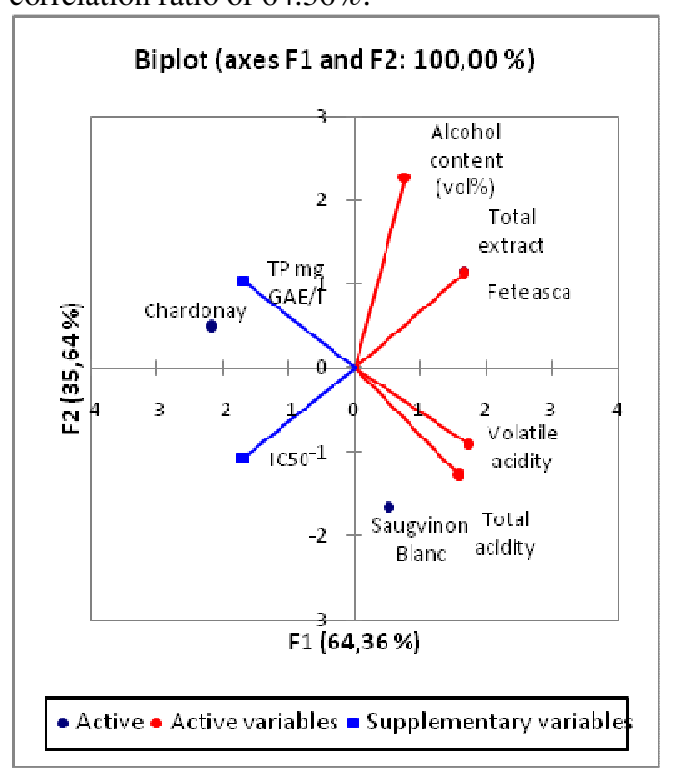

Fig. 2. The relation between the content of total phenols and antioxidant activity in the analyzed white wines samples

Surprising is the fact that on white wine range analyzed was not significantly correlated with antioxidant activity. It is estimated that wines high in extract have pronounced antioxidant activity and the polyphenol content is low $(r=-0.625)$. Total extract is very significant and has positive influence on the alcohol content $(r=0.778)$

\section{Conclusions}

This research presents some studies concerning polyphenol content, free radical scavenging capacity and general chemical analysis in red and white wines, and are comparable to wines produced in other regions of Europe (wineries from Spain, Greece or Portugal). The polyphenol compounds content in the investigated wines contributes to their antioxidant activity. The total polyphenol content determinate in this research is higher in case of Merlot\&Cabernet 2011 vintage (1084.4 mgGAE/L). We found that the total polyphenol content have a 
high correlation with free radical scavenging capacity.

\section{References}

* E-mail address: analeahu@ fia.usv.ro

[1]. MA Soobrattee, VS Neergheen, A LuximonRamma, O.I Aruma and T.Bahorun Mutation res. 579:200-13 (2005).

[2]. M.S. Fernández-Pachón, D. Villaño, M.C. Garcia-Parrilla and A.M. Troncoso, Analytica Chimica Acta 513 113-118, (2004).

[3]. Pilar Zafrilla, Juana Morillas, Juana Mulero, José M. Cayuela, Adela Martínez-Cachá, Francisco Pardo, and José Manuel López Nicolás, J. Agric. Food Chem., 51 (16), 46944700 (2003).

[4]. H. Bae, Jayaprakasha GK, Crosby K, Jifon JL and Patil BS, Plant Foods Hum Nutr. 67(2), 120-128, (2012).

[5]. C. Damian and M. Oroian, Ovidius University Annals of Chemistry, 24 (1), pp.35-38, (2013).

[6]. T.I Lafka, Vassilia Sinanoglou and E. S. Lazos, Food Chemistry 104 1206-1214, (2007).

[7]. Y. El.Rayess et al., Journal of Membrane Science 382, 19 (2011).

[8]. D. Di Majo, M. La Guardia, S. Giammanco, L. La Neve and M. Giammanco, Food Chemistry 111 45-49, (2008).

[9]. M.Cioroi and C. L. Muşat, Cercetări Agronomice în Moldova 4, 132 (2007).

[10]. J.X.Castillo-Sanchez, M.S. Garcia-Falcon, J. Garrido, E. Martınez-Carballo, L.R. MartinsDias and X.C. Mejuto, Food Chemistry 106 18-26 (2008).
[11]. A. Soceanu, S. Dobrinas, V. Popescu and Fl. Moise, Ovidius University Annals of Chemistry 23(2), 163-166 (2012).

[12]. L. Drăghici, G. Râpeanu and T. Hopulele, Ovidius University Annals of Chemistry, 22(1), 15-20 (2011).

[13]. A. Căta, M.N. Ştefănuţ, C. Tănasie and R. Pop, Ovidius University Annals of Chemistry, 21 (1), 15-19 (2010).

[14]. E. Vamanu, Ovidius University Annals of Chemistry 23 (1), 47-52 (2012).

[15]. S.Mironeasa, Codină G.C., Leahu A. and C. Mironeasa, Food and Environment Safety, X (1) 47-52 (2011).

[16]. D. De Beer, E. Joubert, W. C. A. Gelderblom and M. Manley, J. Agric. Food Chem., 51 (4), 902-909 (2003).

[17]. A.Arnous, D. P. Makris, and P. Kefalas, Journal of food composition and analysis 15, 655-665 (2002).

[18]. P. Simonetti, P. Pietta and G. Testolin, J. Agric. Food Chem., 45 (4), 1152-1155 (1997).

[19]. C.Chircu Brad, S. Muste, E. Mudura and O. Bobiş, Bulletin UASVM serie Agriculture 69/2 222-227 (2012).

[20]. A.F. Ruiz, M.S. García-Falcón, M.C. PérezLamela, E. Martínez-Carballo and J. SimalGándara Food Chemistry 113, 53-60 (2009).

Submitted: May $6^{\text {th }} 2014$ Accepted in revised form: November $3^{\text {rd }} 2014$ 